Grace, A. W., and Suskind, Florence H. (1936) Arch. Derm. Syph., N.Y., 34, 65.

Haim, A., and Mathewson, C., Jun. (1937) J. Amer. med. Ass., 108, 961.

Hermann, H. B., and Berman, L. S. (1942) J. Amer. med. Ass., 120, 827.

Joyeux, B., and Dang-Hank-Kien (1939) Rev. méd. française de l'extrême orient, 17, 131.

Reider, R. T., and Canizares, O. (1938) Arch. Derm. Syph., N.Y., 38, 930.

Riou, M. (1937) Bull. Soc. méd.-chir., Indo-chine, 15, 452.

Riou, M., and Dang-vu-Giac (1937) (from Bull. Soc. méd.-chir., Indo-chine, 15, 412) Abst. in Bull. Hyg., Lond., 13, 1.

Saenz, B. (1935) Arch. Derm. Syph., N.Y., 31, 348.

Tasaki, K., and Kaminura, T. (1937) (from J. orient. Med., 27, 117) Abst. in Bull: Hyg. Lond., 13, 3.

Zanzibar, Government of (1936) Annual Medical Report.

\title{
THE INTENSIVE THERAPY OF EARLY SYPHILIS*
}

\author{
By Colonel D. M. PILLSBURY, Major C. J. COURVILLE, \\ Captain R. H. CREDE, Major J. D. MYERS and Major C. R. WISE \\ Of the Medical Corps, Army of the United States
}

Intensive therapy for early syphilis was undertaken in certain medical installations of the United States Army in the European Theatre of Operations in April 1943. Its use was gradually extended, and in September 1943 the Chief Surgeon of the Theatre directed that intensive therapy be administered as the treatment of choice for all patients with early syphilis. To date, over 3,000 patients have received this type of therapy and there has not been any mortality from treatment. The present report is concerned with (1) a summary of the reasons for adopting a short-term method of treatment in military practice, (2) the technique of treatment and morbidity therefrom in a series of 775 cases personally observed by the authors and (3) a summary of " follow-up" studies performed four or more months after completion of treatment in 435 cases.

It is recognized that this report is essentially a progress note in regard to the profound and radical changes which syphilotherapy is undergoing at the present time. With more widespread use of intensive arsenotherapy and, more recently, with the discovery by Mahoney, Arnold and Harris that penicillin has marked spirochaeticidal powers, the great desirability of safe compression of adequate treatment for syphilis into days or weeks, instead of months and years, gives promise of being realized. It has long been apparent to syphilologists that, with prolonged methods of treatment, the benefits of arsphenamine and bismuth therapy were being applied to their full extent in only a small fraction of the patients who ought to receive them for the sake of the public health and of the individual welfare of the patient. Stokes has stated that, in properly operated modern civilian clinics with competent tracing personnel, long-term treatment is satisfactorily carried through in only 25 per cent of early cases, and that in only 50 per cent is ultimately satisfactory although irregular treatment achieved. Cole, Heisel and Stroud have pointed out that such treatment is attained in only a few " top " clinics in the United States and that the performance of the average type of clinic in this regard is even less satisfactory.

Military personnel, although subject to rigid control, often cannot be treated regularly for syphilis under conditions of global warfare. The rapid movement of troops, the difficulties of maintaining a clinical record of treatment which will remain with the patient week in and week out and the varying availability of treatment facilities combine to produce significant and dangerous interruptions in its continuity. Under conditions of active combat, routine treatment of syphilis becomes impossible of accomplishment. The effect of such interruption of treatment is measurable with reasonable exactness on the basis of Padget's study of the long-term (5-10 year) results of treatment for early syphilis in 551 patients. Padget found that cure was attained by 83.4 per cent of the number of patients

*A paper read to the Medical Society for the Study of Venereal Diseases, 29th January, 1944. 
whose treatment during the first six months was by a continuous system, and that this was increased to 90.4 per cent if treatment during the second six months was likewise continuous. (By "continuous" is meant a weekly injection of an arsephenamine or bismuth preparation, with no lapse of more than four weeks allowed during any one course of treatment.)

In contrast to this, Padget found that of those patients whose treatment was intermittent or irregular during the first six months only 53.8 per cent. achieved " cure." This outcome was not altered by further administration of irregular treatment. If, however, later continuous treatment was given, the incidence of "cure" increased to 72.7 per cent. In patients whose treatment during the first six months was continuous, the rate of "cure" was 75 per cent if treatment thereafter was irregular. Padget came to the conclusion that, if continuous treatment cannot be attained, his data strongly suggest that no treatment at all is the desideratum.

Since the original report on intensive therapy by Chargin, Leifer and Hyman appeared in 1935, a large number of papers dealing with this method of treatment have been published. It is not intended to review these in extenso. The most comprehensive review available is that of Moore and the reading of this excellent judicial summing up of intensive therapy experience throughout 1942 is recommended. Excellent summaries have also been published more recently by Stokes, Beerman and Wammock and by Cole, Heisel and Stroud. On the basis of these summaries a comparative table of the effects of intensive and standard arsenotherapy has been drawn up. (See Table 1.) Individual published reports may be found in which the authors' experience has been at variance with some of the statements in this table, but it is believed that it is in good general accord with the combined experience of most observers (Schoch and Alexander ; Bundesen, Bauer and Kendell ; Thomas and Wexler).

On the basis of the published clinical and laboratory experience, certain variations in the schedule of intensive therapy are possible. In selecting a schedule of treatment, various considerations must be taken into account. First and most important is the margin of safety of treatment for the patient ; in Moore's words, "a method which simultaneously cures the disease and kills the patient is, to put it mildly, undesirable'". Secondly, the curative effect must be satisfactory. Thirdly, various corollary but nevertheless important factors must be considered in the selection of a method, including the technical difficulties of various types of treatment, the laboratory tests which are necessary, the amount of skill and experience required on the part of medical officers administering treatment, the time in hospital and the "follow-up" procedures. Those factors which govern the selection of treatment will be considered separately.

\section{Factors which govern the safety of treatment}

(1) The time factor.-The mortality from treatment is in inverse ratio to the time over which the treatment is given (Stokes, Beerman and Wammock; Eagle and Hogan). It seemed to us that the five-day intravenous drip treatment or the ten-day syringe methods, with an inherent mortality of $1: 200-300$, were unjustifiably dangerous. With specialized extremely expert handling it may be possible to reduce this mortality, as is shown by Rattner's series of 481 patients treated by the five-day intravenous drip method without any mortality; but such an experience could hardly be expected in a larger series of patients treated in a number of hospital installations. It was considered that a twenty-day schedule offered a reasonable margin of safety, provided that every precaution was taken to see that the treatment was administered competently, and our experience has justified this prediction.

(2) Technique of administration.- The intravenous drip method offers technical difficulties which are insuperable in the absence of constant nursing attendance. If large numbers of patients are to be treated in military hospitals, a multiple syringe method of administration, such as that introduced by Schoch and Alexander, is essential. 
(3) Medical personnel.-Since few medical officers have had experience in intensive therapy, a system of training under supervision is necessary. In the

TABLE 1-COMPARATIVE EFFECT OF STANDARD AND INTENSIVE THERAPY IN EARLY SYPHILIS

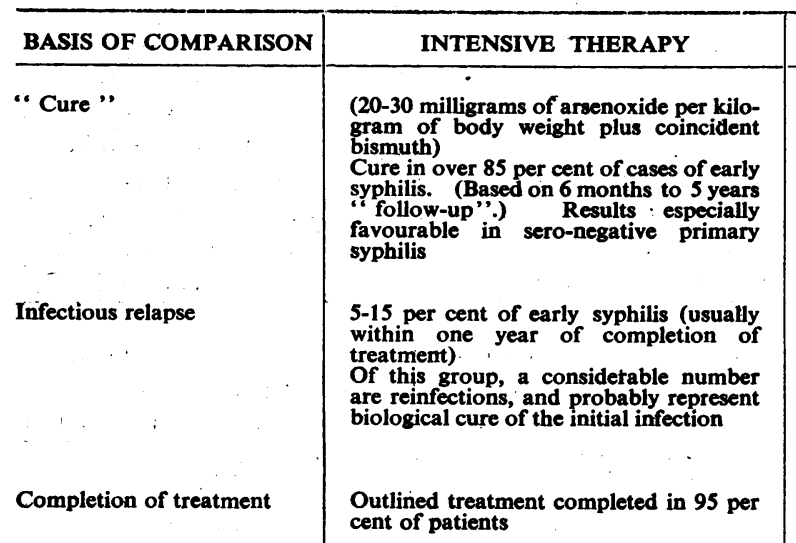

STANDARD THERAPY

(Continuous arsphenamine bismuth system)

Cure in over 85 per cent of cases, provided treatment is carried through without significant interruption

1-15 per cent of all cases (usually within 2 years)

Reinfection not common. Relapse rate increases if treatment is interrupted, especially during initial course of arsenical

Treatment completed within specified length of time in 25-80 per cent of all patients. Under conditions of global warfare, particularly active combat. serious unavoidable interruptions of serious unavoidable inte
treatment are common

Predicted mortality from treatment

Incidence of asymptomatic neurosyphilis in patients completing treatment

Blood serological reversal

Absence from military duty

Place of treatment

Serological re-examination

Spinal fluid examination

Drugis used
0.4 per cent with 5 -day schedule.

$0 \cdot 1-0.2$ per cent with 20 -day schedule. (This has not been borne out by present series).

1 per cent

12-16 weeks.

(20-30 milligrams of arsenoxide per kilogram body weight plus coincident injections of bismuth)

Approximately 25 days under schedule now in use

Special treatment service in hospitals

Quantitative Kahn, every month for 6 months after completion of treatment. Increasing titre of syphilitic reagin predicts relapse

6 to 12 months after completion of treatment

Mapharsen (mapharside) only. Neoarsphenamine cannot be substituted. Bismuth subsalicylate during and after arsenotherapy
Mortality from treatment negligible with arsenoxide-bismuth system

10 per cent

12-16 weeks

(Continuous arsenoxide-bismuth or neoarsphenamine-bismuth systems)

Variable. Under ideal conditions, if treatment facilities are efficient and near-by, the loss of time should be less than with intensive treatment. However, loss of time commonly averages ever, loss of time commonly averages
$\frac{1}{2}$ day per treatment and in specialized
personnel (for example air personnel personnel (for example air personnel grounded after each treatment) the loss treatment is completed

Hospital and field medical installations

Standard Kahn, 3 and 6 months after completion of treatment

6 months or more after initiation of treatment

Mapharsen is considered preferable by almost all American syphilologists ; bismuth subsalicylate

case of officers who are well trained in the field of internal medicine and who have reasonable working knowledge of the methods of diagnosis of early syphilis, opportunity for observing an active intensive treatment service for a period of one week has been found to be adequate. Thorough grounding in internal medicine on the part of the medical officer who administers the intensive therapy is absolutely 
essential. In hospitals in which it is undertaken the chief of the medical service should be made responsible for its supervision.

(4) Criteria for suspension of treatment because of reactions.-These are taken up in some detail below. The principle of " safety first " has always been the governing factor in our cases. "If in doubt, don't treat" is a useful maxim in respect of continuation of intensive therapy in a reacting patient, especially for physicians of less than very wide experience with the method.

(5) Essential laboratory tests.-It is of course advisable that such laboratory tests as are necessary in order to detect unfavourable reactions to treatment be performed. These, however, should be carefully selected, because performance of a large number of tests which may not be necessary makes treatment needlessly complex and throws an unjustifiable burden on the laboratory facilities of the hospital. Performance of all the laboratory tests outlined by Leifer (as summarized by Stokes, Beerman and Wammock) for all methods of intensive therapy would make such treatment extraordinarily burdensome, if not impossible, in Army hospitals in a foreign theatre of operations. With the twenty-day schedule of treatment, increasing experience has led to a constant diminution of the routine laboratory tests required.

\section{Selection and management of cases}

With these considerations in mind, the following principles of selection of patients and of management of treatment were outlined for intensive therapy.

Type of patient.-We use the method in cases of early syphilis only (duration of infection less than one year) in otherwise healthy individuals less than 40 years of age. A shift from standard therapy to intensive therapy is considered allowable if the individual has received less than 10 injections of his first course of mapharsen, without significant reaction to treatment.

Place of administration.-Intensive therapy is permitted only in general hospitals and in other hospitals specially designated. It is prescribed that administration of such therapy is to be under the direction of the Chief of Medical Service, and a system of training of medical officers in such therapy has been evolved.

Management on completion of arsenotherapy.-Patients have been returned promptly to duty after the completion of arsenotherapy, provided that no marked reaction to treatment has occurred. In patients for whom any further bismuth therapy was desired by the medical officer in charge of the patient, it was so indicated on the clinical record of the patient. Many of the patients who received intensive therapy initially were given a course of ten bismuth injections after discharge from the hospital. This, however, is now regarded as optional and a steadily decreasing number of patients are receiving any bismuth therapy in unit lines.

"Follow-up"; serological tests.-It is advised by most observers that " followup " serological tests for syphilis be performed at monthly intervals for the first six months after completion of intensive arsenotherapy. It has been found, however, that in military practice emphasis on performance of such tests at intervals of two months by means of "follow-up requests " insured more satisfactory serological re-examination. (It was not feasible to send such requests at monthly intervals, because of the large amount of routine work involved.) It is recognized that such a procedure represents a compromise, but there has not been any evidence that patients have been subjected to any unwarranted risk thereby ; in fact the reverse has been true. "Follow-up" "Kahn tests, in so far as possible, have been performed by the quantitative method ; significant increase in titre (that is, of the order of $10-80$ units) is regarded as a warning of probable early relapse and treatment is reinstituted immediately. If, however, the Kahn has remained positive with a low titre without change over several months, treatment is not advised within six months after completion of intensive therapy. At this time, or as soon as possible thereafter, a complete study of the patient is 


\section{THE BRITISH JOURNAL OF VENEREAL DISEASES}

carried out, including physical examination for evidence of relapse or progression of the infection, a serological test for syphilis and a spinal fluid examination. Further treatment at this time has rested on the results of such examinations. If they are all negative, the clinical record ("Syphilis Register"') of the patient has been sent to the Medical Records Division for review and safe-keeping. Kahn tests three and six months thereafter have been carried out ; if these are negative the result is regarded as satisfactory.

TABLE 2.-REACTIONS TO INTENSIVE ARSENOTHERAPY

\begin{tabular}{|c|c|c|c|c|c|c|}
\hline \multicolumn{5}{|c|}{. } & Number & Percentage \\
\hline Number of patients treated $\ldots$ & .. & .. & .. & .. & .775 & - \\
\hline Number in whom treatment was completed & .. & .. & .. & .. & 746 & $96 \cdot 3$ \\
\hline \multicolumn{4}{|c|}{ Number in whom treatment was discontinued because of reactions } & . & 29 & $3 \cdot 7$ \\
\hline Secondary fever (6th to 15 th day of treatment) & .. & .. & .. & .. & 97 & $12 \cdot 5$ \\
\hline
\end{tabular}

REASONS FOR DISCONTINUANCE OF THERAPY (THE SECONDARY REACTION)

\begin{tabular}{|c|c|c|c|c|c|c|c|c|c|c|c|}
\hline \multicolumn{2}{|c|}{ Secondary fever } & . & .. & . & . & . & . & . & .. & 17 & 一 \\
\hline Neutropenia & .. & .. & .. & . & . & . & . & . & . & 2 & 一 \\
\hline Hepatitis & $\therefore$ & $\therefore$ & .. & . & $\cdots$ & . & . & - & . & 6 & 一 \\
\hline \multicolumn{3}{|c|}{ Toxicodermal reaction } & . & . & . & .. & . & $\cdots$ & . & 3 & 一 \\
\hline \multicolumn{2}{|c|}{ Encephalopathy. . } & .. & .. & .. & . & . & . & . & $\cdots$ & 1 & - \\
\hline
\end{tabular}

\begin{tabular}{|c|c|c|c|c|c|c|c|c|c|c|c|}
\hline \multirow{2}{*}{\multicolumn{4}{|c|}{ Primary fever over $101^{\circ} \mathrm{F}$. (per os) }} & \multicolumn{2}{|c|}{ OTHER } & \multicolumn{2}{|c|}{ REACTIONS } & TO & \multicolumn{2}{|c|}{ TREATMENT } & \multirow[b]{2}{*}{22} \\
\hline & & & & . & $\cdots$ & $\cdots$ & $\cdots$ & $\cdots$ & $\cdots$ & 170 & \\
\hline \multicolumn{5}{|c|}{ Moderate to severe bismuth stomatitis } & $\therefore$ & . & . & $\cdots$ & $\cdots$ & 5 & - \\
\hline Minor skin & ons & thou & ever & . & $\cdots$ & $\cdots$ & - & $\cdots$ & $\cdots$ & 6 (approx.) & $一$ \\
\hline Neuritis & .. & . & $\cdots$ & $\cdots$ & $\cdots$ & $\cdots$ & $\cdots$ & $\cdots$ & $\cdots$ & 0 & - \\
\hline Nephritis & .. & .. & .. & . & $\cdots$ & $\cdots$ & . & . & $\cdots$ & 0 & 一 \\
\hline
\end{tabular}

\section{Reactions to treatment}

The incidence of reactions to treatment in a series of 775 patients who were personally observed by us from April to December 1943 is given in Table 2.

The various manifestations of the secondary reaction have been studied in some detail in a separate communication by one of us (Crede). With the principles of management of this reaction outlined therein it was possible to complete the course of intensive therapy in all but 4 of 428 patients on whom it was initiated. It is probable that this represents the largest proportion of cases of completed treatment which can be attained with an intensive method as short as twenty days. Furthermore, it has been well brought out that, for reasons which are not easily determinable, competent therapists may at times encounter a succession of cases in which intensive treatment cannot be completed (Cole, Heisel and Stroud). In one series of patients under treatment in a United States Army medical unit, 6 out of 45 patients who were treated by a very competent medical officer developed reactions severe enough to demand discontinuance of therapy. In this series there was a succession of mild or severe blood dyscrasic reactions, which were not explicable on the basis of the current supply of mapharside, of the technique of treatment or of other factors (Jacox). It is probable that an overall percentage of completion of therapy in 95 per cent of patients on whom it is started represents a very satisfactory level for the twenty-day schedule of treatment. Our experience would indicate that severe reactions often occur in close succession. It is wise for any therapist who initiates intensive therapy to keep the fact in mind, that at times a long series of patients may tolerate treatment without reaction and thus 
induce a false sense of security, or, on the other hand, that a succession of reactions to treatment may produce unwarranted discouragement.

Primary fever.-This reaction is not of practical importance as a reason for discontinuing therapy. In patients in whom the fever is $103^{\circ} \mathrm{F}$. or more, it may seem advisable to delay the administration of the second injection until the third day of treatment, but this will be necessary for very few patients, certainly well under 1 per cent.

The three types of reactions which are most alarming, and in the case of which discontinuance of arsenical therapy or prolonged suspension thereof is essential, are (1) blood dyscrasias of severe degree, (2) hepatitis, and (3) encephalopathy.

(1) Blood dyscrasias.-In any patient who has sustained a reaction in which the total polymorphonuclear count has dropped below 1,500 per cubic millimetre (regarding 4,000 as normal), decision as to reinstitution of arsenotherapy must be very carefully considered. The advice of a competent haematologist should be sought. It must be kept in mind that the total white cell count may not be an adequate guide in such cases.

(2) Hepatitis.-The principles of resumption of therapy in patients who have sustained the reaction of hepatitis are well established in prolonged therapy for syphilis. It is ordinarily unwise to resume arsenotherapy within three months after such a reaction, and then only on a cautious dosage schedule. Intensive arsenotherapy should not be reinstituted. There has been no contraindication in our series to continuance of treatment with bismuth, nor, in a few patients, with penicillin.

(3) Encephalopathy.-The reaction of encephalopathy has, fortunately, not occurred frequently during intensive arsenotherapy by the twenty-day method. Because of the sudden and unpredictable onset, the frequent accompaniment of convulsive seizures and the lack of any method of treatment which has been demonstrated to be effective, this reaction is most alarming and spectacular. It is regarded as an absolute contraindication to further arsenotherapy at any time.

Corneal stippling.-A few cases of cornea ${ }^{1}$ stippling have been observed by Capt. F. P. Calhoun ; they occurred between the second and the fifth day after the inception of intensive arsenotherapy. This curious condition is considered as probably being due to irritation of the corneal nerve endings by the drug. It is of no particular significance and clears in a few days in spite of continued treatment with mapharside. It is apparently not an indication to interrupt treatment.

Treatment of reactions with $O X .217$. - Through the courtesy of Dr. R. A. Peters, F.R.S., Whitley Professor of Biochemistry at Oxford, a supply of OX.217 was obtained for the treatment of reactions to intensive arsenotherapy. It has been shown to be of value in the treatment of allergic exfoliative dermatitis due to trivalent arsenical compounds, and its use in reactions to intensive arsenotherapy has seemed logical. Experience with it has not yet been sufficient to determine whether or not it is of value in controlling the secondary reaction ; this is not surprising, in view of the marked variation of the reaction in different patients. The opinion of the authors of this paper is divided on this point. The use of OX.217 is being continued and, in general, the course of patients treated with it has been favourable in regard to prompt subsidence of manifestations of the secondary reaction. The usual dose has been 4 ampoules, each containing 100 milligrams of OX.217, administered intramuscularly during the first 24 hours, and 2 ampoules daily during the succeeding 2 days. The only adverse reaction to OX.217 has been occasional pain at the site of injection and, in one patient, formation of an abscess.

Substitution of penicillin therapy for arsenotherapy in patients intolerant to arsenic

It has been established that penicillin is a highly effective spirochaeticide, produces rapid reversal of the positive serological test and does not produce significant reactions (Mahoney, Arnold and Harris ; Wise and Pillsbury). In circumstances in which the supply of penicillin has been adequate, therefore, patients who have developed intolerance to arsenoxide have immediately been placed on treatment with penicillin. The optimum total dose that is needed for all phases of early syphilis has not yet been established, but at the present time a total dosage of $2,400,000$ units, administered in 60 doses of 40,000 units each at intervals of three hours night and day for a period of 7.5 days, is being used. Further treatment is not given to such patients. A system of close "follow-up", 
which has been found essential to the employment of intensive arsenotherapy, is necessary for the protection of patients who have received penicillin, in order that serological or clinical relapse may not proceed undeteeted. In an appendix we quote the official instructions for the use of intensive therapy for cases of syphilis and the substitution of penicillin for the arsenicals in certain circumstances. (See page 163.)

\section{Subsequent history of intensively treated cases}

In Table 3 are listed the serological tests in a group of 435 patients on whom reports had been received four months or more after completion of treatment. These reports have been received in response to routine "follow-up " requests. It will be noted that the results in the matter of blood serology have been specially favourable in the group of patients for whom treatment was started during the sero-negative primary phase ; only one report of a " doubtful"' reaction was received in this group of 205 patients, with 103 of whom contact had been maintained for six months or more. The results in the group of patients with sero-positive primary syphilis are not as favourable, 7 of 169 such patients showing a positive serological test for syphilis. In the patients of this group who had been reexamined after six months or more, 4 out of 109 were sero-positive.

In the group of patients with frank secondary syphilis and positive serological tests for syphilis at the beginning of treatment, " follow-up " tests four or more months after treatment have been received concerning only 61 patients. Of these 6 are positive and 4 are recorded as doubtful. The total number of patients is not sufficient to be of statistical significance, but it would appear that the " serological response" of this group of patients-at least on the basis of preliminary serological "follow-up" studies-would be the least favourable. In this group of 435 patients there have been 3 instances of serological relapse, 2 of which were noted at the six months examination, after the serological tests for syphilis at four months had been negative; one was noted at nine months, after a negative report at six months.

TABLE 3.-BLOOD SEROLOGICAL TESTS FOR SYPHILIS FOUR OR MORE MONTHS AFTER COMPLETHON OF INTENSIVE ARSENOTHERAPY

LAST REPORTED SEROLOGICAL TEST FOR SYPHILIS AND TIME ELAPSED SINCE END OF TREATMENT

\begin{tabular}{|c|c|c|c|c|c|c|c|c|c|c|c|c|c|c|c|c|}
\hline \multirow[b]{2}{*}{ DIAGNOSIS } & \multicolumn{4}{|c|}{4 months } & \multicolumn{4}{|c|}{6 months } & \multicolumn{4}{|c|}{ 9-12 months } & \multicolumn{4}{|c|}{ All cases } \\
\hline & Total & Pos & Neg. & Dtfl & Total & Pos & Neg & Dtfi & Total & Pos & Neg. & Dtf & Total & Pos. & Neg. & Dtfi \\
\hline $\begin{array}{c}\text { Sero-negative } \\
\text { primary }\end{array}$ & 103 & - & 103 & - & 83 & - & 82 & 1 & 19 & - & 19 & - & 205 & - & 204 & 1 \\
\hline $\begin{array}{c}\text { Sero-positive } \\
\text { primary }\end{array}$ & 60 & 3 & 54 & 3 & 93 & 3 & 90 & - & 16 & 1 & 15 & - & 169 & 7 & 159 & 3 \\
\hline Secondary & 30 & 4 & 24 & 2 & 24 & 2 & 21 & 1 & 7 & - & 6 & 1 & 61 & 6 & 51 & 4 \\
\hline Totals .. & 193 & 7 & 181 & 5 & 200 & 5 & 193 & 2 & 42 & 1 & 30 & 1 & 435 & 13 & 414 & 8 \\
\hline
\end{tabular}

Clinical relapse.-Complete data on the incidence of clinical relapse in all patients who had been treated by intensive arsenotherapy are not as yet available. In the group of patients summarized in Table 2 , two instances of frank clinical relapse were encountered and there were two instances of reinfection which satisfied the requirements outlined by Moore: It is felt that further instances of relapse or reinfection will undoubtedly be encountered in this group. In the entire group of patients treated (over 3,000 ) there have been at least 10 instances of reinfection. It is again emphasized that our data on clinical relapse and reinfection are incomplete. However, the "running incidence" of clinical relapse has certainly not been sufficiently large to lessen confidence in intensive therapy as compared with the results after prolonged therapy. Reinfection (as 
manifested by a new primary lesion) occurs much more frequently after intensive therapy than after prolonged therapy and, as evidence of biological cure of the disease, it may be regarded as an indication of the effectiveness of the method. However, in individuals who repeatedly expose themselves to venereal disease, reinfection represents a problem of some difficulty. It is considered likely that this problem will be encountered even more frequently after the use of penicillin therapy.

Spinal fluid examinations.-In Table 4 the results of spinal fluid examinations performed six or more months after completion of intensive therapy. are summarized. Of the 236 examinations reported, 234 yielded negative results. The

TABLE 4.-SPINAL FLUID EXAMINATIONS SIX OR MORE MONTHS AFTER COMPLETION OF TREATMENT

\begin{tabular}{|c|c|c|c|c|c|c|c|c|c|}
\hline . & & Hal & 80 & & & & Total & Positive & Negntive \\
\hline Sero-negative primary & & .. & . & . & . & .. & 100 & - & 100 \\
\hline Sero-positive primary & $\cdots$ & . & . & $\cdots$ & $\cdots$ & $\cdots$ & 109 & $1 *$ & 108 \\
\hline Totals . . & $\cdots$ & $\cdots$ & - & $\cdots$ & $\cdots$ & $\cdots$ & 236 & 2 & 234 \\
\hline
\end{tabular}

*Wassermann reaction-420 ; lymphocytes, 30 ; total protein, 80 milligrams per cent ; colloidal gold curve 43221000.

This patient showed equivocal changes in the colloidal gold curve and slight increase in total protein. The Wassermann reaction was negative and the cell count normal. The results are probably not of significance, but a riport of later examination has not yet been received.

fluid of one patient was classified as Grade III and the patient was referred for special therapy: In the other patient, the positive findings consisted of an increase in globulin and a low first-zone colloidal gold curve, without any increase in cell count, and a negative complement fixation test. It is doubtful whether or not these changes were of significance, but the patient was referred for further treatment and further "follow-up " studies are not as yet available.

\section{Summary and comment}

(1) Because of the difficulties of carrying out standard prolonged treatment for early syphilis under conditions of global warfare, and because these difficulties produce serious interruptions in treatment which greatly reduce its effectiveness, intensive arsenotherapy for early syphilis was undertaken in selected United States Army hospital installations in the European Theatre of Operations, in April 1943. The initial experience indicated that such therapy could be administered without significant mortality from treatment, and in September 1943 intensive therapy was designated by the Chief Surgeon of the European Theatre of Operations as the treatment of choice for all cases of early syphilis.

(2) The considerations which govern the selection of a twenty-day schedule of treatment are outlined in some detail above.

(3) Over 3,000 patients with early syphilis have received intensive therapy by this method, and there has not been any mortality from treatment. The morbidity, although not excessive, has been sufficient to demonstrate that such treatment should be undertaken only by physicians with adequate training in internal medicine and syphilology, and only in hospitals with adequate nursing staff.

(4) The treatment administered has consisted of a total of 20 milligrams of mapharsen (mapharside) per. kilogram of body weight, administered in 20 equal doses by the syringe technique within a period of 20 days. Eight injections of bismuth salicylate ( 0.2 gramme of the salt each) were administered intramuscularly during the same period. A considerable percentage of the number of patients 
also received a subsequent course of ten weekly injections of bismuth, but this procedure has now been largely discontinued.

(5) The complete absence of mortality from treatment has been due, it is believed, to several factors, as under.

(a) The selection of a schedule of treatment in which the " curative " dose of arsenoxide is given over a period of not less than twenty days. With the five-day intravenous drip or the ten-day multiple syringe method, the predicted mortality is 1 in 200-300. With schedules of treatment extending over a period longer than five days, the factor of sensitization to arsenoxide becomes increasingly important, but this type of reaction is more easily controlled and less dangerous than are those induced by a greater mass of the drug injected within a short period of time. Moreover, on a schedule in which injections are given at daily intervals, it is unlikely (although obviously possible) that a dose of arsenoxide will be given to a patient who has already begun to develop a severe reaction from a previous injection, provided that reasonable caution is exercised. With shorter schedules of treatment, it is entirely possible to administer another dose of arsenical to a patient who is already reacting badly but whose reaction has not reached a level at which it is clinically apparent.

(b) The type of personnel treated. Only two female patients were included in our series. This is undoubtedly an important factor in the favourable mortality experience, because serious reactions to intensive arsenotherapy are more frequently encountered in the female.

(c) The selection, training and supervision of medical officers assigned to the administration of intensive arsenotherapy.

(d) The administration of intensive therapy only in designated hospitals with well qualified nursing staff and adequate consultation facilities.

(6) In a series of 775 consecutive patients with early syphilis treated by us, treatment was completed in 96.3 per cent. The reactions which necessitated the discontinuance of intensive therapy were secondary fever, hepatitis, neutropenia, toxicodermal reaction and encephalopathy.

(7) Fever is the most valuable single warning signal of reaction to twenty-day intensive therapy. With treatment of this duration severe reaction almost never occurs in the absence of a significant rise in temperature. In the case of a physician with wide experience in the method, it is believed that it would be possible to dispense with almost all routine laboratory studies directed toward detection of reactions, and to restrict such tests to patients in whom fever develops. Patients in whom fever does not develop may be treated on an ambulatory status in the hospital and may be assigned to light duties about the ward or the hospital grounds:

(8) The immediate clinical course of patients who receive intensive therapy has been satisfactory in regard to the healing of mucocutaneous lesions, although this is no more rapid than that which occurs during the initial two injections of mapharside in prolonged therapy.

(9) Data as to the incidence of clinical and serological relapse and of persistent sero-positivity in our series of patients are incomplete, and are subject to revision when further re-examination material is available. It would appear, however, that the results in sero-negative primary syphilis, based on serological " followup " studies in 205 patients, will be extremely good, and that the results in other types of early syphilis will be comparable to those obtained by standard prolonged treatment, continuously administered.

(10) The incidence of positive spinal fluid reactions in 236 tests performed six or more months after completion of intensive therapy is less than 1 per cent.

\section{Conclusions}

It is concluded that the method of intensive therapy employed in this series of patients has a clear and decisive superiority over prolonged methods of treatment in regard to a completion of the outlined therapy within the prescribed period of time. It has relieved the unit medical officer of much of the burden of the management of syphilis on prolonged schedules. The chief disadvantages of intensive therapy are the greater incidence of serious reactions, as compared with a prolonged mapharsen-bismuth system, and the necessity of initial confinement to 
hospital for a period varying from twenty to thirty days. The preliminary reports available would indicate that the "follow-up" results as to clinical relapse and serologic tests for syphilis in our patients will be satisfactory, and that the incidence of positively reacting spinal fluid will be lower than that which is encountered after prolonged methods of treatment.

\section{REFERENCES}

Bundesen, H. N., Bauer, T. J., and Kendell, H. W. (1943) J. Amer. med. Ass., 123, 816. Chargin, L., Leifer, W., and Hyman, H. T. (1935) J. Amer. med. Ass., 104, 878.

Cole, H. N., Heisel, E. B., and Stroud, G. (1943) J. Amer. med. Ass., 123, 253.

Crede, $\mathbf{R}$. $\mathbf{H}$. In press.

Eagle, H., and Hogan, R. B. (1943) Vener. Dis. Inform., 24, 159.

Jacox, R. F., Personal communication.

Mahoney, J. F., Arnold, R. C., and Harris, A. (1943) Vener. Dis. Inform., $24,355$.

Moore, J. E. (1941) The Modern Treatment of Syphilis, 2nd ed., Baltimore.

Padget, P. (1940) Amer. J. Syph., 24, 692.

Rattner, H. (1943) J. Amer. med. Ass., 122, 986.

Schoch, A. G., and Alexander, L. J. (1942) Arch. Derm. Syph., N.Y., 46, 128.

Stokes, J. H. (1942) J. Amer. med. Ass., 120, 1093.

- Beerman, H., and Wammock, V. S. (1943) Amer. J. med. Sci., 206, 521.

Thomas, E. W., and Wexler, Gertrude (1943) Arch. Derm. Syph., N.Y., 47, 553.

Wise, C. R., and Pillsbury, D. M. (1944) Brit. J. Surg., 32, 214.

\section{APPENDIX}

The following directive letter on penicillin therapy was sent to all hospitals in the European Theatre of Operations, United States Army, which are authorised to administer such treatment.

\section{Subject: Schedule of Intensive Therapy for Early Syphilis.}

1. Circular letter No. 138, 10 Sept. 1943, Office of the Chief Surgeon, provides for the administration of intensive therapy for early syphilis at all General Hospitals and such other hospitals as the Chief Surgeon may designate, and provides that the Chief Surgeon will prescribe the schedule of such treatment. The following outline of the present recommended schedule is set down for the guidance of the responsible medical officers in such designated hospitals. It is not intended that the recommendations contained herein will be used to the exclusion or neglect of other indicated therapeutic or nursing procedures.

2. Training of medical officers. It is essential that medical officers who have had no previous experience in intensive treatment become familiar with such therapy on the basis of personal observation. In units designated for such treatment it is advisable that the medical officer in charge of intensive therapy be assigned to detached service for a period of not less than one week in a hospital in which considerable numbers of patients are under such treatment. Arrangements for this training may be made on request to the Base Section Surgeon.

3. Schedule of intensive treatment for early syphilis.

$a$ Period of treatment-not less than 20 days.

$b$ Drugs and Dosage.

(1) Arsenoxide. The total dose of Mapharsen or Mapharside will be $20 \mathrm{mgm}$. per kilo body weight. In individuals in whom treatment proceeds without significant reactions, this amount will be given in twenty equal doses over a period of twenty days, i.e. a daily dose of $1 \mathrm{mgm}$. per kilo body weight. A total dose of $1500 \mathrm{mgm}$. will not be exceeded in any patient, and in obese patients, adjustment of the total dose on the basis of the patient's optimum weight is advisable. In patients who have received some previous treatment on the standard 26-week schedule, the total dose of arsenoxide given, including that previously administered, should be 25 mgm. per kilo body weight. The remaining Mapharsen necessary to reach this dose may be divided into daily doses not exceeding $75 \mathrm{mgm}$. per day.

Example : A patient weighing 70 kilos has received 10 injections of Mapharsen, of $60 \mathrm{mgm}$. each, on the standard treatment schedule. If shifted to intensive therapy he should receive a total dose of $70 \times 25 \mathrm{mgm}$. or $1750 \mathrm{mgm}$. Taking into account the $600 \mathrm{mgm}$. which he has already received this would leave a " balance " of $1150 \mathrm{mgm}$. to be given. This may be given in daily doses of $70 \mathrm{mgm}$. for 16 days. However, in patients in whom there have been gross interruptions in initial treatment, or in whom there has been any evidence of relapse, or in whom a high blood Kahn titer is obtained, it is advisable to administer the full course of 20 days of therapy on a $20 \mathrm{mgm}$./kilo dosage schedule.

(2) Bismuth. During the period of 20 days of treatment, 8 doses of $2 \mathrm{cc}$. $(0.13 \mathrm{gm}$. metallic bismuth) each of $10 \%$ suspension of bismuth salicylate should be given. In patients who are transferred from routine to intensive therapy, 2 cc. of bismuth should be given on an average of every 2.5 days during the period of treatment.

$c$ Diet. Special diets are not essential. 


\section{THE BRITISH JOURNAL OF VENEREAL DISEASES}

\section{The following clinical and laboratory examinations are essential :-}

a Preliminary examinations should include careful and thorough physical examination, urinalysis, complete blood count; temperature, and record of previous idiosyncrasies to any drugs, and quantitative blood Kahn. Preliminary spinal fluid examination is useless in frank early syphilis.

$b$ Essential examinations during treatment.

(1) Hemoglobin determination $1 \mathrm{x}$ weekly.

(2) Total W.B.C. and differential $2 x$ weekly.

(3) Urinalysis $1 \mathrm{x}$ weekly.

(4) Quantitative Kahn preceding and following treatment.

(5) Temperature record.

(6) Observation by medical officer twice daily.

$c$ None of the foregoing is intended as any stricture on the performance of such special laboratory tests as may be deemed indicated for investigational or therapeutic purposes. However, care must be observed to avoid overtaxing the facilities of the hospital laboratory concerned, by tests which are not essential.

\section{Complications of treatment.}

Complication

Primary fever

(Herxheimer)

Secondary fever

Toxicodermal reaction

\begin{abstract}
Manifestation
Fever after initial injection of

Mapharsen. Temperature usually

normal on following morning.

Fever usually occurring on the 5th to 12th day of treatment. If temperature does not exceed $101^{\circ} \mathrm{F}$. by mouth, and is normal on morning following treatment the course of therapy may ordinarily be continued. However fever is the most valuable However fever is the most valuable of reactions, and decision as to continuance of therapy should be dependent on careful examination and judgment.
\end{abstract}

Fever plus itching and/or inflammatory skin lesions of varying severity.

Toxic

encephalopathy

Mild to severe mental confusion, headache, fever, convulsive seizures in some cases, coma. Spinal fluid sometimes shows marked increase in protein.

Jaundice

Usually fever, g.i. symptoms and clinical jaundice.
None.

Treatment

Symptomatic.

Force fluids.

Symptomatic. Force fluids. baths. OX 217 intramuscularly. 200-400 mgm. daily.

No satisfactory treatment. Spinal fluid drainage, hyperrepeated small transfưsions adrenalin or benzedrine. Place on seriously ill - list.

As for acute catarrhal jaundice. High protein intake.

Suspension of treatment. Repeated small transfusions. Administer OX 217 . $100 \mathrm{mgm}$. $4 \times$ daily intramuscularly for 2 days. tonic glucose by vein,

Further Intensive Therapy Reaction may usually be disregarded, and therapy continued.

If temperature has been above $101^{\circ} \mathrm{F}$., allow 1 day of rest, and then proceed with test dose of $.001 \mathrm{gm}$. of arsenoxide.

Ordinarily not a contraindication to fever therapy. Always an indication for caution, and use of small test dose of arsenoxide on resumption.

An absolute contra-indication to further arsenical therapy.

No arsenical for four months. Intensive therapy not to be re-instituted.

Further arsenical therapy contra-indicated.

only, as a rule. Total white under 5000 . or relative neutro (under $50 \%$ ) quently encountered grave reaction to 20 day intensive therapy.

On the 20 day schedule the reactions of hematuria, marked proteinuria, peripheral neuritis, and thrombosis, have been encountered so infrequently as to make discussion of them unnecessary.

6. Further treatment of patients in whom intensive arsenotherapy is discontinued because of reactions will be dependent on many factors, and individualization will be necessary. The following general rules apply, on the basis of present knowledge.

a. In patients in whom a total of 800 mgms. of arsenoxide has been given, particularly if the blood Kahn is negative or is of low titer, the risk of relapse or progression of the patient's infection is probably not sufficient to justify the risk of further arsenical therapy. However, in such patients, a total of at least 15 injections of bismuth should be given, 0.2 gms. weekly. Also it is advisable that such patients have a blood Kahn test at intervals of one month, in order that a significant increase in titer may be discovered promptly.

b. In patients in whom the total amount of arsenoxide has been less than $800 \mathrm{mgm}$., and providing the reaction is of a type which does not contra-indicate further arsenical therapy at a later date, it is recommended that a course of treatment be outlined to provide a total dose of arsenoxide of $30 \mathrm{mgm}$./kilo body weight, and a total of 16 doses of bismuth subsalicylate. As penicillin becomes available in greater supply it is planned to treat the syphilitic infection of such patients with penicillin and not attempt any further arsenical therapy. 


\section{CLINICAL RECORDS}

7. Under conditions of movement of troops in a theater of operations, follow-up examinations may not always be possible at the scheduled time. Adequate check-ups will sometimes depend on the understanding and knowledge which the soldier has about this infection. At the time the diagnosis of syphilis is established, the medical officer responsible has an unparalleled responsibility and opportunity to acquaint the patient with the nature of his disease, his chance of cure by intensive therapy, the importance of follow-up serological and spinal fluid tests, and the importance of reporting any lesion suggesting mucocutaneous relapse. The Supplementary Record of Treatment, ETOUSA MD Form 313, will be filled out and given to each patient, and the times for further laboratory or clinical examinations indicated thereon. This is in addition to the Syphilis Register (Form 78).

8. Treatment of patients with coincident gonorrhea or chancroid and early syphilis. Penicillin is the drug of choice for the treatment of gonorrhea in such patients. However, if penicillin is not available for this purpose, there has been no indication that patients in good general physical condition will not ordinarily tolerate combined sulfonamide and intensive Mapharsen therapy. In such patients, sulfadiazine is the sulfonamide of choice, because of its lower sensitizing properties.

\section{CLINICAL RECORDS}

\section{A CASE OF GONOCOCCAL URETHRITIS IN THE MALE, WITH STRICTURE, PERI-URETHRAL STONE AND CORPUS SPONGIOSUM FISTULA}

In October 1943, a tall powerful Thames bargeman, 65 years old and a bachelor, was sent up to hospital for "carcinoma of penis". He presented a swollen convoluted glans penis jutting out from the swollen convoluted prepuce of an old-standing paraphimosis.

Sinuses opened in the deep furrows between the convolutions of the glans on both sides, while on the left lay a larger whiter and very hard convolution of apparently fibrosed corpus spongiosum, the distal slope of which ended in a shallow furrow holding the small opening of a sinus. A probe passed along this sinus struck on stone and, on squeezing the glans, pus sprang from every furrow.

The displaced meatus led to a stricture, which admitted only a probe, situated at level of dorsal sulcus.

Fig. 1.-Stone in glans penis shown by $x$-ray examination.

The whole stank with the foul odour of infected urine and, on micturition, urine escaped from the glans in thin discrete spouts on all sides, with one bigger frontal spout from the meatus.

$\mathrm{X}$-ray (Fig. 1) revealed a stone underneath the white hard convolution of glans on left side, thus conforming to the discovery made by probing.

Microscopical examination of the pus showed gonococcus, coliform bacterium, streptococcus, diphtheroid. Wassermann and Kahn blood tests (repeated) were strongly positive. No other evidence of syphilis was detected.

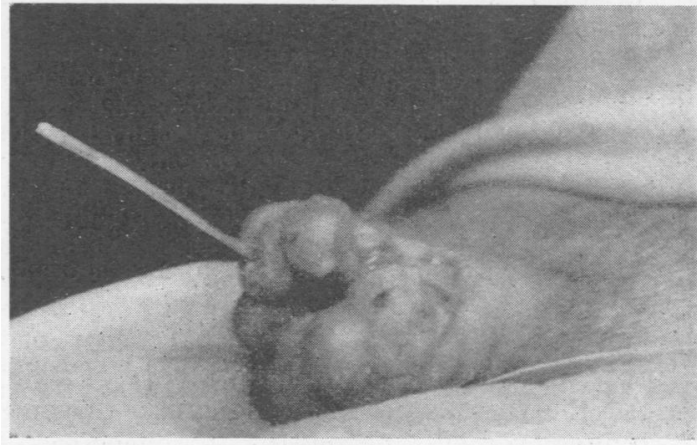

Fig. 2.-Probe in meatus. 